\title{
GAMBARAN KEJADIAN DEPRESI POSTPARTUM DI WILAYAH KERJA PUSKESMAS 2 SOKARAJA
}

\author{
Khamidah Achyar ${ }^{1}$, Wulan Margiana ${ }^{2}$ \\ E-mail: khamidahachyar30@gmail.com \\ Program Studi Kebidanan DIII Fakultas Ilmu Kesehatan, Universitas Muhammadiyah Purwokerto \\ Jl. Supardjo Rustam Km.7 PO BOX 229 Purwokerto 53181 Telp. (0281)6844253
}

\begin{abstract}
ABSTRAK
Angka kejadian depresi postpartum (DPP) di wilayah Indonesia sekitar 10-20\%, hal ini sama dengan beberapa negara lainnya seperti di India dan Iran. Gejala DPP dapat dikenali dengan gangguan mood. Adapun penyebab DPP yaitu usia muda, dirawat di rumah sakit, non-inisiasi menyusui dini, inkontinensia urin, multiparitas, fungsi kesehatan mental, status sosial rendah, dan masalah kesehatan fisik.

Penelitian ini bertujuan untuk mengetahui angka kejadian deperesi pada ibu nifas (Depresi PostPartum) di wilayah kerja Puskesmas 2 Sokaraja Jumlah responden sebanyak 29 orang. Desain penelitian dengan menggunakan Crossectional. Hasil penelitian ini yaitu kejadian depresi postpartum di wilayah kerja Puskesmas 2 Sokaraja sebanyak 10,2\%. Usia responden antara 20-35 tahun (96,6\%), pendidikan SMA $(62,1 \%)$. pekerjaan IRT $(82,2 \%)$, status menikah pertama $(96,6 \%)$, primipara $(44,8 \%)$, tempat bersalin di puskesmas $(75,9 \%)$, semua mendapatkan pelayanan faskes, periode masa nifas $>14$ hari $(89,7 \%)$, jenis persalinan pervaginam $(89,7 \%)$,semua responden tidak mempunyai riwayat penyakit, tidak ada yang riwayat stress dan tidak ada yang mengalami komplikasi kehamilan, komplikasi persalinan $(17,2 \%)$, semua mendapat pendampingan persalinan dan bantuan merawat bayi.

Kesimpulan: Ibu nifas di wilayah kerja Puskesmas 2 Sokaraja ada yang mengalami DPP.
\end{abstract}

Kata Kunci: Depresi Postpartum, Puskesmas

\section{Pendahuluan}

Periode nifas minggu pertama merupakan periode yang rentan karena masa adaptasi, sehingga permasalahan yang timbul pada periode ini segera diatasi agar tidak berdampak pada kejadian komplikasi masa nifas maupun perkembangan pola asuh. Prevalensi depresi postpartum sekitar 7-20\%. ${ }^{1}$ Hasil penelitian di India juga menyebutkan prevalensi depresi pada 3 dan 12 bulan setelah melahirkan adalah $11,8 \%$ dan di Côted'Ivoire $16,1 \%$ dan $8,9 \%$ dan di Ghana $7,2 \%^{1}$ sementara hasil penelitian di Sumatera, menunujukkan prevalensi postpartum depresi sebesar $12.5 \%{ }^{2}$

Depresi postpartum memiliki efek merusak pada anak-anak dan keluarga. Kesehatan ibu nifas dipengaruhi oleh faktor fisik maupun psikologis. ${ }^{3}$ Ibu postpartum yang mengalami depresi berefekpada penyakit demam pada anak-anak, dengan kemungkinan demam pada anak sekitar 1,57 kali dibandingkan ibu yang tidak mengalami depresi postpartum. ${ }^{1}$

Hasil penelitian mengidentifikasi bahwa gejala depresi postpartum yaitu dengan menentukan suasana hati ibu. Hasil identifikasi penelitian menunjukkandimensi yang berhubungan yaitu pengucilan sosial, perilaku bayi dan isolasi sosial antara ibu yang mengalami migran. Kontribusi yang paling besar dalam penelitian ini adalah harapan ibu. Penelitian ini membuktikan ada Pengaruh perinatal pada suasana hati depresi postnatal. ${ }^{4}$

Wanita yang rendah penyesuaiannya akan mengalami Stress dan depresi yang lebih tinggi pada kasus korban kekerasan seksual dan kekerasan fisik selama kehamilan. Pada kelompok lain ditemukan bahwa akan lebih tinggi dialami pada depresi postpartum. ${ }^{5}$ Variabel prediktor postpartum depresi yaitu usia ibu yang muda, ibu dirawat di rumah sakit, non-inisiasi menyusui dini, inkontinensia urin, multiparitas, fungsi kesehatan mental yang rendah, status sosial rendah dan kesehatan fisik yang berfungsi rendah. ${ }^{6}$

\section{Metode Penelitian}

Metode penelitian ini metode deskriptif, dengan menggunakan desain penelitian cross-sectional. Populasi pada penelitian ini yaitu ibu nifas yang berada di 
wilayah kerja Puskesmas 2 Sokaraja. Peneliti mengujungi responden ibu nifas dengan bantuan bidan desa dan mahasiswa praktik kebidanan komunitas pada kunjungan nifas pada rentang waktu minggu pertama postpartum atau lebih, untuk melakukan pemeriksaan nifas dan pemantauan psikologis dengan menggunakan daftar pertanyaan Epidenburgh Postpartum Depression Scale. Adapun jumlah responden dalam penelitian ini yaitu sebanyak 29 orang ibu nifas dengan menggunakan total sampling ibu nifas yang ada selama 1 bulan dari Desember 2016Januari 2017. Lokasi penelitian yaitu di wilayah kerja Puskesmas 2 Sokaraja.

\section{Hasil dan Pembahasan}

A. Hasil

Jumlah responden dalam penelitian ini sebanyak 29 ibu nifas. Angka kejadian depresi postpartumdan beberapa karakteristik ibu nifas di wilayah kerja Puskesmas 2 Sokaraja dapat dilihat berdasarkan distribusi frekuensi tabel berikut.

\section{Tabel 1. Distribusi Frekuensi Usia} Responden

\begin{tabular}{|c|c|c|}
\hline Usia & Jumlah & $\%$ \\
\hline$<20$ tahun & 1 & 3,4 \\
\hline 20-35 tahun & 28 & 96,6 \\
\hline Total & 29 & 100 \\
\hline
\end{tabular}

tahun yaitu sejumlah 28 orang $(96,6 \%)$.

Tabel 2. Distribusi Frekuensi Pendidikan Responden

\begin{tabular}{lll}
\hline Pendidikan & Jumlah & \% \\
\hline SMP & 10 & 34,5 \\
SMA & 18 & 62,1 \\
PT & 1 & 3,4 \\
Total & 29 & 100 \\
\hline
\end{tabular}

Pendidikan responden paling banyak yaitu SMA sejumlah 18 orang $(62,1 \%)$.

Tabel3. Distribusi Frekuensi Pekerjaan Responden

\begin{tabular}{lll}
\hline Pekerjaan & Jumlah & \% \\
\hline IRT & 24 & 82,2 \\
Pekerja/swasta & 5 & 17,2 \\
Total & 29 & 100 \\
\hline
\end{tabular}

Pekerjaan responden paling banyak yaitu IRT sejumlah 24 orang $(82,2 \%)$.

Tabel 4. Distribusi Frekuensi Pernikahan

\begin{tabular}{lll}
\hline Pernikahan Jumlah & Jumlah & \% \\
\hline Pertama kali & 28 & 96,6 \\
Kedua/dst & 1 & 3,4 \\
Total & 29 & 100 \\
\hline
\end{tabular}

Responden menikah pertama berjumlah 28 orang $(96,6 \%)$.

Tabel 5. Distribusi Frekuensi Jumlah Persalinan

\begin{tabular}{lll}
\hline Persalinan & Jumlah & \% \\
\hline Pertama & 13 & 44,8 \\
Kedua & 12 & 42,4 \\
Ketiga & 4 & 13,8 \\
Total & 29 & 100 \\
\hline
\end{tabular}

Responden dengan persalinan pertama adalah paling banyak yaitu 13 orang $(44,8 \%)$

Tabel 6. Distribusi Frekuensi Tempat Bersalin

\begin{tabular}{|c|c|c|}
\hline Tempat Bersalin & Jumlah & $\%$ \\
\hline Puskesmas & 22 & 75,9 \\
\hline Rumah Sakit & 7 & 24,1 \\
\hline Total & 29 & 100 \\
\hline
\end{tabular}
banyak menggunakan fasilitas kesehatan di puskesmas sebanyak 22 orang $(75,9 \%)$.

Tabel 7. Distribusi Frekuensi Periode Masa Nifas

\begin{tabular}{lll}
\hline Periode Masa Nifas & Jumlah & \% \\
\hline$<14$ hari & 3 & 10,3 \\
$>14$ hari & 26 & 89,7 \\
Total & 29 & 100 \\
\hline
\end{tabular}

Periode masa nifas responden paling banyak $>14$ hari yaitu sebanyak 26 orang $(89,7 \%)$.

Tabel 8. Distribusi Frekuensi Jenis Persalinan

\begin{tabular}{lll}
\hline Jenis Persalinan & Jumlah & \% \\
\hline Normal & 26 & 89,7 \\
SC & 3 & $10,3 \%$ \\
Total & 29 & 100 \\
\hline \multicolumn{2}{c}{ Jenis persalinan responden paling } \\
banyak normal sebanyak 26 orang $(89,7 \%)$
\end{tabular}


Tabel 9. Distribusi Frekuensi Riwayat Penyakit

\begin{tabular}{lll}
\hline Riwayat Penyakit & Jumlah & $\mathbf{\%}$ \\
\hline Ada & 0 & 0 \\
Tidak Ada & 29 & 100 \\
Total & 29 & 100 \\
\hline
\end{tabular}

Responden tidak ada yang mempunyai riwayat penyakit

Tabel 10. Distribusi Frekuensi Komplikasi Kehamilan

\begin{tabular}{lll}
\hline $\begin{array}{l}\text { Komplikasi } \\
\text { kehamilan }\end{array}$ & Jumlah & $\mathbf{\%}$ \\
\hline Tidak ada & 0 & 0 \\
Ada & 29 & 100 \\
Total & 29 & 100 \\
\hline
\end{tabular}

Responden tidak ada yang mengalami komplikasi kehamilan

Tabel 11. Distribusi Frekuensi Komplikasi Persalinan

\begin{tabular}{lll}
\hline $\begin{array}{l}\text { Komplikasi } \\
\text { Persalinan }\end{array}$ & Jumlah & $\%$ \\
\hline Tidak ada & 24 & 82,8 \\
Ada & 5 & 17,2 \\
Total & 29 & 100 \\
\hline \multicolumn{1}{c}{ Responden } & yang & mengalami
\end{tabular}
komplikasi persalinan sebanyak 5 orang $(17,2 \%)$

Tabel 12. Distribusi Frekuensi Riwayat stres

\begin{tabular}{lll}
\hline Riwayat Stress & Jumlah & \% \\
\hline Tidak ada & 29 & 100 \\
Ada & 0 & 0 \\
Total & 29 & 100 \\
\hline \multicolumn{2}{r}{ Semua esponden tidak ada } & yang \\
mengalami riwayat stress sebelumnya.
\end{tabular}

Tabel 13. Distribusi Frekuensi Usia Suami

\begin{tabular}{lll}
\hline Usia Suami & Jumlah & \% \\
\hline $20-40$ tahun & 27 & 83,2 \\
$>40$ tahun & 2 & 6,8 \\
Total & 29 & 100 \\
\hline \multicolumn{2}{c}{ Usia suami responden terbanyak dalam }
\end{tabular}
rentang 20-40 tahun yaitu 27 orang $(83,2 \%)$
Tabel 14. Distribusi Frekuensi Pendidikan

Suami

\begin{tabular}{lll}
\hline Pendidikan Suami & Jumlah & \% \\
\hline SMP & 4 & 13,8 \\
SMA & 8 & 27,6 \\
PT & 17 & 58,6 \\
Total & 29 & 100 \\
\hline \multicolumn{2}{c}{ Pendidikan suami responden terbanyak }
\end{tabular}

PT(Pendidikan Tinggi) yaitu 17 orang $(58,6 \%)$

Tabel 15. Distribusi Frekuensi Pemberian uang belanja

\begin{tabular}{|c|c|c|}
\hline $\begin{array}{l}\text { Pemberian } \\
\text { belanja }\end{array}$ & uang Jumlah & $\%$ \\
\hline $\mathrm{Ya}$ & 29 & 100 \\
\hline Tidak & 0 & 0 \\
\hline Total & 29 & 100 \\
\hline
\end{tabular}

Semua responden mendapatkan uang belanja dari suami.

Tabel 16. Distribusi Frekuensi Pendampingan persalinan

\begin{tabular}{lcc}
\hline $\begin{array}{l}\text { Pendampingan } \\
\text { persalinan }\end{array}$ & Jumlah & $\mathbf{\%}$ \\
\hline Didampingi & 28 & 96,6 \\
Tidak didampingi & 1 & 3,6 \\
Total & 29 & 100 \\
\hline \multicolumn{2}{c}{ Suami responden } & yang mendampingi \\
persalinan sebanyak 28 orang $(96,6 \%)$.
\end{tabular}

Tabel 17. Distribusi Frekuensi Membantu istri merawat bayi baru lahir

\begin{tabular}{|c|c|c|}
\hline $\begin{array}{l}\text { Membantu istri } \\
\text { merawat BBL }\end{array}$ & Jumlah & $\%$ \\
\hline $\mathrm{Ya}$ & 29 & 100 \\
\hline Tidak & 0 & 0 \\
\hline Total & 29 & 100 \\
\hline
\end{tabular}

bantuan dari suami dalam merawat BBL.

Tabel 18. Distribusi Frekuensi Pelayanan petugas kesehatan

\begin{tabular}{lcl}
$\begin{array}{l}\text { Kesesuaian } \\
\text { pelayanan }\end{array}$ & Jumlah & \% \\
\hline Ya & 29 & 100 \\
Tidak & 0 & 0 \\
Total & 29 & 100 \\
\hline \multicolumn{2}{c}{ Semua } & responden \\
pelayanan yang sesuai di KIA. & mendapatkan
\end{tabular}


Tabel 19. Distribusi Frekuensi Skor depresi

\begin{tabular}{|c|c|c|}
\hline Skor EPDS & Jumlah & $\%$ \\
\hline$<10$ & 26 & 89,8 \\
\hline$>10$ & 3 & 10,2 \\
\hline Total & 29 & 100 \\
\hline
\end{tabular}

B. Pembahasan

1) Berdasarkan hasil penelitian ini ibu nifas yang mendapatkan skor EPDS > 10 sebanyak 3 orang $(10,2 \%)$. Hal ini dapat disimpulkan sebagai angka kejadian depresi postpartum di wilayah kerja Puskesmas 2 Sokaraja sebanyak 10,2\%. Hasil penelitian dari beberapa jurnal kejadian depresi postpartum persentasi beragam sekitar sekitar 7$35 \%$. Hasil penelitian menyebutkan prevalensi depresi pada 3 dan 12 bulan setelah melahirkan adalah $11,8 \%$ dan 16,1\% ( di Côted'Ivoire) dan 8,9\% dan $7,2 \%$ (di Ghana) $)^{1}, 10-15 \%^{7}$ dan $34,8 \%^{8}$ sementara hasil penelitian di Sumatera, menunujukkan prevalensi postpartum depresi sebesar $12.5 \%{ }^{2}$

2) Karakteristik ibu nifas berdasarkan hasil penelitian ini sebagai bagian dari faktor-faktor penyebab terjadinya depresi postpartum yaitu:

a) Usia responden. Berdasarkan penelitian di kota Ilam, Iran Barat bahwa rata-rata usia ibu postpartum 27-33 tahun. ${ }^{8}$ Berdasarkan penelitian di Sweden bahwa usia meningkatkan kejadian depresi, semakin lanjut usianya maka semakin berisiko terjadi depresi sekitar 1,25 kali. ${ }^{9}$

b) Pendidikan. Berdasarkan hasil penelitian. Taherifard,et.al. Perbedaan yang signifikan bahwa wanita yang memiliki tingkat pendidikan rendah adalah faktor risiko signifikan yang paling penting terkait dengan PPD (Postpartum Depression). ${ }^{8}$

P) Perjaan. Berdasarkan
penelitianTaherifard,et.al.
Perbedaan yang signifikan diamati antara skor depresi sebelum dan sesudah melahirkan menunjukkan bahwa ibu yang dipekerjakan dibandingkan dengan pembantu rumah tangga lebih berisiko terhadap PPD. Berdasarkan hasil penelitian Lewis BAdiantara wanita yang bekerja di luar rumah, tidak ada perbedaan antara mereka yang bekerja penuh waktu. ${ }^{8}$

d) Status pernikahan. Berdasarkan penelitia Maria Muzik, et.al. BahwaFaktor (demografi, sejarah, dan gestasional), Riwayat pelecehan anak, risiko demografi, dan jumlah gejala PTSD seumur hidup meningkat kehamilan-Onset risiko PTSD, sedangkan lobus gejala PTSD gestasional paling baik diprediksi oleh sementaraTrauma dan kegelisahan tenaga kerja. Wanita dengan gejala PTSD terbesar meningkat selama kehamilan tersebut Paling mungkin menderita depresi pascamelahirkan dan melaporkan penurunan hubungan ikatan bayi mereka pada 6 minggu pascapersalinan. ${ }^{10}$

e) Periode masa nifas.Berdasarkan penelitian Maliszewska K,et.al.bahwa Secara keseluruhan, 48 pasien $(12,40 \%)$ ditemukan berisiko mengalami depresi pascamelahirkan antara minggu keempat dan delapan setelah melahirkan. Sindrom pramenstruasi dan EPDS> 12 poin selama minggu pertama setelah melahirkan meningkatkan risiko depresi pascakelahiran. ${ }^{11}$

f) Jenis persalinan. Berdasarkan penelitian Taherifard,et.al. Perbedaan yang signifikan diamati antara skor depresi sebelum dan sesudah melahirkan. Jenis persalinan, status sosial ekonomi rendah, dan perempuan memiliki tingkat pendidikan rendah adalah faktor risiko signifikan yang paling penting terkait dengan PPD. ${ }^{8}$ 
g) Riwayat penyakit, komplikasi kehamilan dan persalinan. Berdasarkan hasil penelitian Surkan PJ,et.al. bahwa penyakit selama tiga bulan pascapersalinan pertama adalah faktor risiko untuk gejala depresi, dengan hubungan yang kuat untuk kejang dan penyakit

hepatobiliari. ${ }^{12}$ Berdasarkan hasil penelitian Lara-Cinisomo $\mathrm{S}$, Kurang dari sepertiga wanita mengalami depresi pada saat pendaftaran. Depresi pralahir, PPD, dan kecemasan dikaitkan secara signifikan dengan penghentian menyusui dini (yaitu, berhenti menyusui sebelum 2 bulan). Ada interaksi yang signifikan antara penghentian menyusui dini dan status depresi pada OT pada minggu ke 8 postpartum. ${ }^{13}$

h) Riwayat stress. Berdasarkan hasil penelitianSilverman,et.al. dalam studi berbasis populasi terbesar sampai saat ini, risiko PPD (Postpartum Depression) lebih tinggi 20 kali lebih untuk wanita dengan riwayat depresi, dibandingkan wanita tanpa riwayat. Demikian juga berdasarkan hasil penelitian Bina Rriwayat depresi merupakan prediktor signifikan gejala PPD. ${ }^{9}$

i) Usia suami dan tingkat pendidikan suami responden. Berdasarkan penelitian Prenoveau J, et.al. bahwa calon ayah juga mengalami tingkat depresi saat menanti kelahiran bayinya. Berdasarkan penelitian Prenoveau ini bahwa proporsi yang signifikan dari calon ayah menunjukkan gejala depresi selama periode perinatal. Depresi antenatal ayah dapat secara signifikan memprediksi tingkat depresi pascamelahirkan ayah yang lebih tinggi. Faktor risiko psikososial secara konsisten dikaitkan dengan depresi ayah dalam berbagai titik waktu. ${ }^{14}$

j) Status ekonomi.Berdasarkan hasil penelitian Bina R,et.al. bahwa penghasilan dan jumlah kehamilan di masa lalu merupakan prediktor signifikan gejala PPD. ${ }^{15}$

k) Dukungan suami.Berdasarkan penelitian Morais AODS,et.al. BahwaGejala depresi pada kehamilan dan postpartum dikaitkan dengan skor depresi yang lebih tinggi, yang mengindikasikan adanya gangguan pada hubungan ibu / anak. Efek terbesarnya adalah gejala depresi pada kehamilan. Faktor lain yang terkait dengan skor PBQ yang lebih tinggi adalah dukungan sosial yang lebih rendah, status sosial ekonomi yang tidak menguntungkan, dan hidup tanpa pasangan, oleh asosiasi tidak langsung. ${ }^{16}$

\section{Kesimpulan}

a. Jumlah responden dalam penelitian ini 29 orang ibu nifas. Hasil analisi ini dapat disimpulkan sebagai angka kejadian depresi postpartum di wilayah kerja Puskesmas 2 Sokaraja sebanyak 10,2\%.

b. Usia ibu nifas antara 20-35 tahun $(96,6 \%)$. Pendidikan responden sebagian besar SMA (62,1\%). pekerjaan responden paling banyak yaitu IRT $(82,2 \%)$. Responden menikah pertama $(96,6 \%)$. responden paling banyak dengan persalinan pertama adalah paling banyak (44,8\%), tempat bersalin responden paling banyak menggunakan fasilitas kesehatan di puskesmas (75,9\%) dan mendapatkan pelayanan yang sesuai di KIA. Periode masa nifas responden paling banyak $>14$ hari $(89,7 \%)$. Jenis persalinan responden paling banyak normal $(89,7 \%)$. Semua responden tidak mempunyai rowayat penyakit sebelumnya, tidak ada yang riwayat stress, tidak ada yang mengalami komplikasi kehamilan, ada yang mempunyai komplikasi persalinan $(17,2 \%)$. Usia suami responden 
terbanyak dalam rentang 20-40 tahun 27 orang $(83,2 \%)$, pendidikan suami responden terbanyak PT(Pendidikan Tinggi) (58,6\%), semua responden mendapatkan uang belanja dari suami dan mendapatkan dukungan pendampingan persalinan maupun perawatan bayi baru lahir.

\section{Daftar Pustaka}

[1] Guo N., Bindt C., Bonle M.T., Poku J.A., Hinz R., Barthel D., Koffi M., Posdzich S., Deymann S., Barkmann C., Schlüter L., Jaeger A.,Nguah S.B., Eberhardt, K.A., NGoran E., Tagbor H, and Ehrhardt S. Association of Antepartum and Postpartum Depression in Ghanaian and Ivorian Women With Febrile Illness in Their Offspring: A Prospective Birth Cohort Study. Am J Epidemiol. 2013;178(9):1394-1402

[2] Nasution S.K., Gambaran Karakteristik Demografi Penderita Sindrom Depresi Postpartum Di Rumah Sakit Umum Daerah Dr. Pirngadi Kota Medan. Tesis FK Universitas Sumatera Utara. 2011

[3] Schiller C.E., Brody S.M., Rubinow D.R. The Role of Reproductive Hormones in Postpartum Depression.CNS Spectr. 2015 February ; 20(1): 48-59

[4] Eastwood J., Jalaludin B.,Kemp L., Phung H., Barnett B.,Tobin J. Social Exclusion, Infant Behavior, Social Isolation, And Maternal Expectations Independently Predict Maternal Depressive Symptoms. Brain and Behavior 2013; 3(1): 14-23 doi: 10.1002/brb3.107

[5] Flanagan J,C., Gordon K.C., Moore T.M., Stuart G.L., Women's Stress, Depression, and Relationship Adjustment Profiles as They Relate to Intimate Partner Violence and Mental Health During Pregnancy and Postpartum. Psychol Violence. 2015 January ; 5(1): 66-73.

[6] Sword W, Kurtz Landy C, Thabane L, Watt S, Krueger P, Farine D, Foster G. Is Mode Of Delivery Associated With Postpartum Depression At 6 Weeks: A Prospective Cohort Study. BJOG 2011;118:966-977.
[7] Ahmadpanah M, Nazaribadie M, Aghaei E, Ghaleiha A, Bakhtiari A, Haghighi M, Bahmani DS, Akhondi A, Bajoghli $\mathrm{H}$, Jahangard L, Holsboer-Trachsler E, Brand S. Influence Of Adjuvant Detached Mindfulness And Stress Management Training Compared To Pharmacologic Treatment In Primiparae With Postpartum Depression.Arch Womens Ment Health. 2017 Jul 18.

[8] Taherifard P, Delpisheh A, Shirali R, Afkhamzadeh A, Veisani Y. Socioeconomic, psychiatric and materiality determinants and risk of postpartum depression in border city of ilam, Western iran. Depress Res Treat. 2013;2013:653471.

[9] Silverman ME, Reichenberg A, Savitz DA, Cnattingius S, Lichtenstein P, Hultman CM, Larsson H, Sandin S. The risk factors for postpartum depression: A population-based study.Depress Anxiety. 2017 Feb;34(2):178-187. doi: 10.1002/da.22597. Epub 2017 Jan 18.

[10] Maria Muzik, M.D., Ellen W. McGinnis, M.S., Erika Bocknek, Diana Morelen, Katherine Rosenblum, Israel Liberzon, Julia Seng, and James L. Abelson. PTSD Symptoms across Pregnancy and Early Postpartum Among Women with Lifetime PTSD Diagnosis. Depress Anxiety . 2016 July ; 33(7): 584-591.

[11] Maliszewska K, Bidzan M, ŚwiątkowskaFreund M, Preis K. Medical and psychosocial determinants of risk of postpartum depression: a cross-sectional study. Acta Neuropsychiatr. 2017 May 31:1-9.

[12] Surkan PJ, Sakyi KS, Christian P, Mehra $\mathrm{S}$, Labrique A, Ali $\mathrm{H}$, Ullah B, Wu L, Klemm R, Rashid M, West KP, Strobino DM.Risk of Depressive Symptoms Associated with Morbidity in Postpartum Women in Rural Bangladesh. Matern Child Health J. 2017 Aug 1.

[13] Lara-Cinisomo S, McKenney K, Di Florio A, Meltzer-Brody S. Associations Between Postpartum Depression, Breastfeeding, and Oxytocin Levels in Latina Mothers. Breastfeed Med. 2017 Jul 27. 
[14] Prenoveau J, Craske M, Counsell N, West V, Davies B, Cooper P, Rapa E, Stein A. Postpartum GAD is a risk factor for postpartum MDD. The course and longitudinal relationships of postpartum GAD and MDD.Depress Anxiety. 2013 Jun;30(6):506-14.

[15] Bina R, Harrington D. Differential Predictors of Postpartum Depression and Anxiety: The Edinburgh Postnatal Depression Scale Hebrew Version Two Factor Structure Construct Validity.Matern Child Health J. 2017 Jul 28. doi: 10.1007/s10995-017-2345-5.

[16] Morais AODS, Simões VMF, Rodrigues LDS, Batista RFL, Lamy ZC, Carvalho CA, Silva AAMD, Ribeiro MRC. Maternal depressive symptoms and anxiety and interference in the mother/child relationship based on a prenatal cohort: an approach with structural equations modeling. Cad Saude Publica. 2017 Jul 13;33(6) 